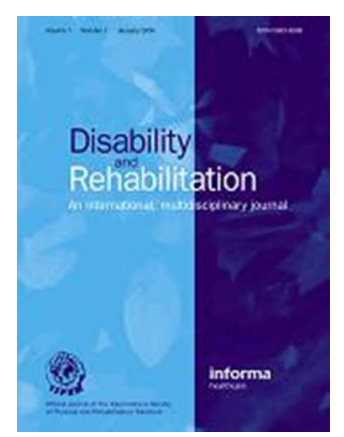

\title{
Living with chronic neuropathic pain after spinal cord injury: An Interpretative Phenomenological Analysis of community experience
}

\begin{tabular}{|r|l|}
\hline Journal: & Disability and Rehabilitation \\
\hline Manuscript ID: & TIDS-08-2014-022.R1 \\
\hline Manuscript Type: & Research Paper \\
\hline Keywords: & $\begin{array}{l}\text { biopsychosocial, acceptance, pharmacological treatment, spinal cord injury, } \\
\text { social isolation, pain }\end{array}$ \\
\hline
\end{tabular}

\section{SCHOLARONE ${ }^{\text {m }}$}

Manuscripts

This is an Accepted Manuscript of an article published by Taylor \& Francis in Journal of Disability and Rehabilitation on 20/01/2015, available online: http://www.tandfonline.com/10.3109/09638288.2014.1002579 


\section{Implications for Rehabilitation}

- Chronic NP after SCI is often described as worse than the injury itself, often impacting upon the sufferers physical and psychological health.

- The experiences of persons with SCI-specific NP highlight the impact of pain on their physical, psychological and social health. This indicates that healthcare professionals should incorporate a biopsychosocial approach for managing pain post-SCI.

- Routine clinical follow-up of SCI patients with chronic NP, as well as comprehensive pain management treatment programmes, could address the three themes evidenced in the current study, by moving routine intervention with NP away from pain relief, towards pain management.

- Continued education for patients, friends, family members, and healthcare professionals may be beneficial in promoting understanding and awareness of $\mathrm{NP}$ and its consequences following SCI. 


\title{
Living with chronic neuropathic pain after spinal cord injury: An Interpretative Phenomenological Analysis of community experience
}

\author{
Purpose: This paper presents an in-depth, idiographic study examining the lived \\ experience of chronic pain following spinal cord injury (SCI). Neuropathic pain \\ (NP) occurs in a large majority of the SCI population and is particularly \\ intractable to treatment. It can be both psychologically and physically \\ debilitating. This study examines how the experience of NP is mediated by its \\ meaning to the sufferer.
}

Method: Semi-structured interviews were conducted with eight people with SCI and chronic NP, attending outpatient clinics at a specialist SCI Centre in the UK. Verbatim transcripts were subjected to interpretative phenomenological analysis in order to further understand the experience.

Results: Analysis suggested that NP has powerful consequences upon the sufferer's physical, psychological, and social well-being, in line with a biopsychosocial understanding of pain. Three super-ordinate themes were identified: a perceived gap between treatments received and participants' views of what they wanted and needed; a fight for life control and acceptance; and feeling understood by others with SCI, but isolated from the non-understanding able-bodied.

Conclusions: The results are discussed in terms of the possible application of acceptance-based therapy to NP and the potential for the alleviation of the debilitating consequences of NP. 


\section{Introduction}

A large body of evidence suggests that over $60 \%$ of spinal cord injured (SCI) individuals experience chronic pain $[1,2]$. Approximately half of the SCI population suffers with neuropathic pain (NP); pain resulting from central nerve damage [3]. NP is often described as severe or excruciating [4], and has specific consistent self-reported sensory qualities, including burning, electric, and crushing, that can be intrusive and distressing [5]. NP is persistent and can be continuous or intermittent, often fluctuating in severity and worsening over time [2, 6]. Siddall, McClelland and Rutkowski [7] found that NP had increased in intensity, and was present in between $34 \%$ and $41 \%$ of the SCI population, at five years post-injury.

Described by some of those with SCI as worse than the injury itself, chronic pain may be the most difficult aspect of SCI to manage [8]. NP can negatively affect an individual's physical function [9], such as their ability to return to work and daily activities [8], and quality of life [10]. Chronic NP may also serve as a risk factor to psychological well-being and adjustment to injury [1,11].

Neuropathic pain places SCI patients at increased risk of depression $[12,13]$ as well as lower self-ratings of mood and quality of life [14]. Additionally, depression and pain are rated as more severe when coinciding [15] with diagnosis and treatment of one being adversely affected by the other [16]. Ullrich, Lincoln, Tackett, Miskevics, Smith, and Weaver [17] argue that pain and depression amplify one another, and that consistent pain and depression after SCI suggests treatment-resistant problems. As such, increased understanding of neuropathic pain, in particular, after SCI is important in order to develop interventions that may prevent the potentially debilitating consequences [18].

The accepted view of pain comes from the biopsychosocial model [19]. This incorporates biological factors such as physiological mechanisms, psychological factors 
including cognitive appraisals, mood, and behavioural responses, and social factors such as relationships and the environment. Despite this, however, in routine clinical practice, pharmacological treatments currently dominate the available treatments for SCI-related pain [20]. As well as, for some, limited effectiveness in pain relief, a number of unwanted side effects may also occur [21]. The current literature base for NP suggests that its pathological mechanisms are complex and not fully understood [22] and so absolute pain relief may not necessarily be a realistic goal. There remains a dearth of evidence relating to psychological and social aspects of pain management techniques specific to the needs of the SCI population.

Currently, quantitative SCI-specific pain research appears to dominate the literature. This has offered valuable explanations for the persistence of chronic NP after SCI, including catastrophising [23], and solicitous responses from available social support [24, 25]. However, limited qualitative work has been conducted, focussing upon social support after injury [26], memories of pain [27], experiences of pain management [28], pain acceptance [29], and questions that those with SCI have regarding their pain [30], rather than the experience of pain itself. Other studies [31;32] have explored patients' perspectives of chronic NP through the use of focus groups, identifying medication failure, and the need to learn to live with pain as key issues. The understanding that can be obtained from personal experiential stories of individuals, particularly of chronic NP, can benefit the literature by improving understanding of factors that maintain distress and disability associated with pain. These personal stories, however, appear to have been neglected [33].

An effective method for achieving an in-depth understanding of the lived experience of chronic NP post-SCI is phenomenology. Phenomenology is the study of lived experience, in which the researcher allows the participant to discuss their 
experience in their own terms and context, whilst remaining aware and open to previously unanticipated issues. Interpretative Phenomenological Analysis (IPA) [34] utilises phenomenology, and was conducted on eight interviews with SCI outpatients with chronic NP, in order to gain an in depth understanding of the experience of chronic neuropathic pain and its meaning to those who live with it. IPA uses interpretation to understand "what personal and social experiences mean to the people who experience them' $[35$, p. 178$]$. IPA has the ability to illuminate existing quantitative literature by understanding experiences through analysing accounts from those living with the phenomenon of study.

This study aims to achieve a rich understanding of the experience of chronic NP post-SCI in order to explore what those living with it consider important in their experience. This may offer an enhanced ability for friends, families, and healthcare professionals (HCPs) to understand NP and to provide support to those living with it. Pain management techniques may also be utilised or developed as a result of the specific needs identified by those living with SCI-specific NP.

\section{Method}

\section{Participants}

Participants were recruited from outpatient clinics at The National Spinal Injuries Centre, Stoke Mandeville Hospital. Clinic staff contacted 19 patients meeting the inclusion criteria: one year post-discharge, in order to allow for adjustment to injury and community reintegration; NP present for a minimum period of three months, in order to meet the International Association for the Study of Pain [36] definition of chronic pain; no significant cognitive impairment; 18 years or over; and English speaking, due to the nature of the qualitative methodology. Of the 19 patients contacted, eight declined to participate and 11 were interviewed, after which three were discarded due to insufficient 
data, characterised by interviews that were cut short due to interruptions and time constraints. The participants represent a self-selecting sample, such that they had experiential knowledge of the specific phenomenon of study [37], and the impact of the pain was sufficiently motivating for them to agree to participate. The final sample thus consisted of eight participants, in accordance with recommendations of a small sample size [38], five of which were male, three of which were female. Participants have been given pseudonyms in order to preserve confidentiality and anonymity. Their characteristics are listed in Table 1.

Insert Table 1 here

\section{Procedure}

Local ethical approval was secured for the study from The National Health Service Research Ethics Committee and other relevant local committees.

Nurses preparing patients for a clinic with a medical consultant approached patients with information regarding the study and asked if they would consider taking part, after which they were provided with detailed information and offered time to consider their consent. Written consent was obtained prior to interviews, which were conducted in participants' homes. Interviews were conducted by the first author, and lasted between 40 and 120 minutes.

Data were collected from audio-recorded, semi-structured interviews. The interview schedule, composed of largely open-ended questions, was composed in conjunction with the second and last authors, who work with SCI and chronic pain patients. Each interview started with the question, 'Tell me about your experience of pain since your spinal cord injury'. Participants were given freedom to lead the interview. Unrestricted by the imposition of topics, they were able to discuss their 
experience in terms of their own personal context, focussing on what was most important to them. This allowed for themes to emerge from participants, rather than from the interviewer. An interview schedule was developed in order to elicit further information from participants where necessary. This is presented in Table 2. Any identifying information was changed at the stage of transcription to protect the identities of participants, their friends and families, and HCPs.

Insert Table 2 here

\section{Data Analysis}

Interviews were transcribed verbatim and read a number of times prior to conducting IPA, as recommended by Smith, Flowers \& Larkin [37]. Emergent themes were developed, aided by analytic (descriptive, linguistic, and conceptual) notes and reflections. Super-ordinate themes were abstracted through interrogation of emergent themes to make connections. This resulted in a table of super-ordinate themes, within which were sub-ordinate themes with quotes illustrating each theme.

Analysis followed an idiographic, 'bottom-up' approach, studying one account fully before moving on to the next, in order to appreciate each individual experience in its own light, and consistently checking that themes were grounded in the data and representative of the participant's experience. After each participant's interview was analysed, patterns were established across cases, identifying convergences and divergences across experiences. The researcher analysed iteratively, constantly moving between part and whole and revisiting data in order to ensure that analysis remained grounded in the data. Super-ordinate themes present across at least half of the sample were then identified through cross case analysis. 
The interpretative nature of IPA suggests that individual researchers are likely to interpret data differently, according to personal contextual backgrounds. Determined efforts to 'bracket off' prejudgements and information learned from previous interviews were made through the use of a reflective diary and focussing on the participants' accounts so as to remain true to their experiences. In order to ensure rigour and quality in the analysis, the second and fifth authors were enrolled as independent auditors, both of whom have experience with chronic pain or SCI patients. After analysis of each account, the auditors checked the super-ordinate themes and corresponding quotations to ensure themes were grounded in the data. The auditors discussed thoughts and interpretations in order to illuminate areas of the experience that may have been more easily identifiable to them. The interpretations presented here are therefore considered credible and meaningful, although it is acknowledged that these are not the only interpretations of the data [37]. Sufficient data are included in order to validate themes and interpretations.

\section{Results}

Three super-ordinate themes illuminated the experiences of chronic pain. All patients described their primary pain problem as NP. Super-ordinate themes and their corresponding sub-ordinate themes are presented in Table 3. The quotes that are provided are those that best illustrate the theme.

Insert Table 3 here.

The Chasm Between Biomedical Perspectives and Patient Beliefs and Needs 
The first super-ordinate theme of the chasm was the most prevalent theme, voiced by all participants, and playing a central role in their experiences of pain. The participants felt that the biomedical approach offered inadequate pain relief, non-collaborative patientstaff relationships, and feelings of disempowerment.

\section{Excessive Reliance on Insufficient Medication}

Participants placed a central focus upon the inadequacies of medication, with a shared sense of resentment of relying on medication, despite such inadequacies, and sideeffects that were often considered to be worse than the pain itself. Consequently, some participants chose not to adhere to their drug regimes, either self-medicating, or abandoning their drug regime completely. Harry voiced concerns about the dramatic effect of medication upon his psychological well-being:

$(\ldots)^{1}$ it makes no difference whether I have them and I'm not prepared to take high doses constantly, and be a zombie, and I'd rather put up with a bit of pain than take those drugs and have a blank mind (...) It's like your thoughts are trying to fight their way through a thick lump of fog (...) And once you are on a high dose of course it's very difficult to get off them [Harry].

Harry outlines the negative consequences of his medication, which appeared to outweigh the potential benefits, with his choosing to prioritise his psychological wellbeing and clarity. This is reflected in Harry's desire to not 'be a zombie', implying that he is unable to think clearly due to his medication, which creates a battle for conscious awareness in which Harry's thoughts have to 'fight their way through a thick lump of fog'. Harry is one participant who had chosen to abandon his prescribed drug regime in order to preserve psychological function, and who also touches upon the potential for dependency, illuminating a further worry regarding the medication reliance.

\footnotetext{
${ }^{1}(\ldots)$ represents removed text
} 
For Emma, the ineffectiveness of her drug regime, even at its highest dose, appeared to induce significant distress, and frustration towards her care team:

I would say eight, nine, ten [on a visual analogue scale of pain intensity] ${ }^{2}$ where I'm crying and I feel like I'm in a pit of fire, actually I'm shouting at you because I want you to try and help me with my drugs, and I'm on the phone to my GP saying, "what can I do now? I'm in pain" (...) I'm on 1,200 [mg], I'm on top dose Gabapentin generic, and it's not helping, what do I do now? [Emma].

Emma described great difficulty in achieving satisfactory pain relief, even at the highest dose of pain medication. She comments on repeatedly asking her GP 'what do I do now?' in the hope of obtaining different management advice. The metaphor 'a pit of fire' in Emma's quote provides evidence for psychological and sensory distress.

\section{Losing Faith in Healthcare Professionals}

Five of the eight participants voiced concerns relating to a progressive loss of faith in the healthcare system due to unmet expectations. Participants expressed disappointment and sometimes resentment towards those involved in their care. Harry was one who reflected on his dissatisfaction with medical staff:

The consultants haven't got all the answers; you know (...) they'll fill you up with mind-altering drugs in the hope that it will help you but (...) not for me [Harry].

Harry's quote relates to his resentment of 'mind-altering' medication, whilst also exhibiting a displeasure towards staff who are unable to provide a better alternative. Instead, Harry sees his care team relying on medication without knowing if it will benefit him. He sees these attempts as well meaning, but inadequate. Medical staff are perceived as struggling to find answers and behaving with possibly misplaced certainty. The problematic measurement and treatment of chronic pain in general, and repeated failures to 'solve the problem', with patients desperately searching for cures, may make

\footnotetext{
${ }^{2}$ [text in square brackets] represents descriptive information provided by the author
} 
it more difficult for care teams to 'hear' the experience. Sharon described a dispute that supports the theme of losing faith in HCPs:

Nobody told me I would be so disabled because of this pain. It is not fun. The [community] physiotherapists don't care if you hurt. They say "they give you medication so you don't hurt so you have to do this exercise" [imitating physiotherapists]. "But it hurts" [speaking as herself]. "It doesn't hurt, you just think it does" [imitating physiotherapists]. It does hurt! [Sharon].

Sharon described her community physiotherapists' inability to acknowledge her pain as real experience. Sharon feels that her physiotherapists do not believe in her pain, as though they know better. Sharon's tone was resentful and suggested she finds her physiotherapists' choice of language condescending. Sharon described an inadequate, almost dictatorial, patient-staff relationship that left her void of hope that the physiotherapists could help.

\section{Lack of Input into own Care}

A third theme contributing to the chasm was the participants' sense of a lack of input into their own care. Participants stated that they had asked for particular treatments or medications, but were often refused, leading to feelings of disempowerment and a loss of control over their lives. Emma articulated this particularly strongly:

I went to my GP and I felt so frustrated that my whole life was being judged by someone else in order to say "no, well, we know better than you". As much as it's my [said with emphasis] experience, it's my pain, I'm telling you my experience, you don't seem to be listening because you're not giving me what works for me [Emma].

Emma discussed encounters with her care team where she was refused medication that she had requested. It may be that, perhaps, Emma feels as though her life is being controlled by the decisions of her care team, who may wish to prioritise medication that they favour. This loss of control may be distressing, particularly as she has also lost control of some of her body as a result of the SCI. 


\section{The Battle for Ultimate Agency in Life}

The second super-ordinate theme, voiced by seven of the eight participants, was the sense of being engaged in an ongoing battle against their pain for life control, with an adversarial relationship with the pain. This theme is also closely tied with painacceptance, with those reporting an increased sense of acceptance winning their battle by choosing to stop fighting, and those reporting lower acceptance levels losing control to the pain.

\section{Pain is Winning}

Five of the participants appeared to feel that they were mostly losing against their pain. When pain was winning, participants described an inability to live and make choices about their own lives. Some were more willing to surrender control to their pain, whilst others desperately attempted to escape the pain in order to reduce its grasp on their lives. These attempts were futile, often resulting in further resentment of pain and an increase in pain intensity. Daniel appeared to have lost all hope of regaining control over his life again. When asked how his pain made him feel, he responded:

Just like horrible and low. I feel depressed (...) Because there's no little light at the end any more, it's just like a big black hole. Because it it, it's it's just like, it's never going to end. [Daniel].

This quote illustrates the damaging psychological consequences Daniel associated with his chronic NP. He uses imagery associated with emptiness and lack of control 'like a big black hole'. Daniel suggests that he may have relinquished his hope for a life without pain and has given up hope of winning his battle, illustrated through his use of the idiom 'no light at the end of the tunnel any more'. This catastrophic thinking appears to be associated with Daniel's distress, and average pain intensity of nine on the VAS. 
Rebecca also articulated this theme particularly strongly and appeared to be struggling to function adequately with her pain present. The effect of this passage is cumulative, and it is therefore essential to present a number of quotations together in order to provide rich support the theme:

That's life, and I don't mind being disabled. I don't mind being paralysed, because I can use my arms, and I'm thankful every day for the use of my arms (...) So everything's brilliant it's just the pain and so, hard. And it's just, just so agonising (...) the burning and stinging, it's like fire, and it's just, ugh. It's just like fire, it's horrible. [Rebecca].

It's always been there, the worst thing in my life that's one thing when I do pass away, not looking forward to it yet though, but when I do, I know I'll be smiling in the back of my mind, I'll be thinking at least there'll be no more pain. [Rebecca].

Rebecca made comments surrounding her dislike of the pain throughout her interview; coping with her pain was a struggle that appeared to dominate her sense of recovery and adjustment to the changes brought by the SCI. She articulated acceptance of her injury, but appeared not to accept her pain. Although Rebecca did not have any plans to end her life, she commented on her death, suggesting that death may be her only escape from her pain. The comments presented here may be indicative of her struggle to live with pain present, suggesting that pain is winning. Her average pain intensity was a maximum of ten on the VAS.

\section{I am Winning}

In contrast to those who appeared to be losing the battle, two participants appeared to be winning, and were able to live their lives with little disruption, despite the presence of pain. These participants placed less focus on the fight to defeat pain, describing it as something that was present but they were able to live with. Harry is an example of a participant accepting his pain as a part of his identity, and able to live with it present: $100 \%$, it's me. It's my identity. It's who I am. It's what happens to me. [Harry]. 
If you get a day of pleasure, it erases all memories of the pain, it's remarkable the way the brain works. So, you know, life isn't abject misery for me because I have pleasurable days. [Harry].

Harry's quote implies that he knows pain is sometimes in control but also that pain can be 'trumped' by his other experiences, including pleasure. He suggests an ebb and flow to experience rather than an outright fight. Harry seemed to be well adjusted to his pain, accepting its presence without letting it completely dominate his life and control or impact upon his good days. For Harry, the battle may be a malleable concept, in which the pain may be in control some days, but he seems to be ultimately winning his ongoing battle for control of his life, if not control of pain.

Sean is another participant who did not feel that he had to fight against the pain:

It [pain] hasn't held me back so far (...) just like carrying around another bag I suppose. Don't think about it. It's just another weight ... something I can deal with that I'm not too fussed about, you know, doesn't get in the way as much as possibly other people's responses to pain ... ${ }^{3}$ I can't see it holding me back at all really. [Sean].

Sean appraised his pain more positively, which may have been associated with an average daily pain rating of four, one of the lowest pain ratings given by the group. Here, Sean suggests that you have to carry the bag, but you can manage the weight of it. Those who were winning the battle acknowledged that the presence of pain had the potential to restrict their ability to live life they way they wanted, but not totally. The acceptance of NP as part of their lives and identities may benefit their overall coping.

\section{The Coexistence of Social Cohesion and Social Alienation}

The third emerging super-ordinate theme was that of the simultaneous sense of belonging and isolation. In this, participants felt supported by the understanding SCI community, but also reported feeling alienated from the non-understanding able-bodied

\footnotetext{
${ }^{3}$... represents a pause in speech
} 
community. The importance of social support, particularly from other SCI patients, was acknowledged by five of the participants. Despite the acknowledgement of the usefulness of social support, participants purposely chose to exclude themselves from the able-bodied community and create boundaries in order to avoid becoming a burden.

\section{SCI Population are United but Alone in their Experience}

Participants agreed that they felt understood by other SCI individuals with chronic NP, due to their direct experience of it, and that this was beneficial for their psychological well-being. An essence of resentment towards the non-understanding able-bodied community existed, however, due to the difficulty in describing NP and the able-bodied lack of experience of it. As such, participants reported feelings of isolation from the 'real world'. James is one such participant who commented on the difficulty in articulating pain adequately for able-bodied understanding. He then compared their understanding to that of those with a SCI:

No matter how much family and friends, partners etc., they can believe that they understand, they will never ever truly be able to grasp how painful things are, because you can't physically describe it (...) unless you experience it, you can't. [James].

James' quote suggests that anyone not experiencing chronic pain will struggle to understand it. Further, it suggests that perhaps James also sees it as part of the uniqueness of SCI-specific pain. He also blames himself for not being able to explain the pain adequately. This statement sums up the feelings of the participants within this theme effectively; reflecting his belief that only the SCI population can understand the pain, and that having a SCI is the only way in which to achieve a thorough understanding.

Sharon agreed, contributing evidence for both feelings of unison and isolation:

Unless you're in the wheelchair I know people say "I understand how you feel", but they [able-bodied] don't, you [interviewer] don't [crying] but they do on the website 
[specialised global online SCI community] because they're living that too. It's a great website for support, resources, if you just want to blow off steam, you can do that. It's a great place. [Sharon].

Sharon's distress lay in the fact that the able-bodied do not understand, even where they believe and say that they do, because they are not living the same experience. However, Sharon had instant, direct access to an online network of SCI individuals. She perceived this SCI community as able to provide her with some of the understanding and support she desired. In contrast to her presentation of her experiences with HCPs, she felt that, in the online community, she could discuss her pain and her injury without judgement.

\section{Painful Self as an Affliction on Social Relationships}

Participants felt that their pain had a negative impact on loved ones, and struggled with a sense themselves as a potential burden. Protective strategies included self-imposed social withdrawal and refusal to talk about pain, despite acknowledging the potential benefits of discussing pain with others. When discussing the effect of his pain upon his wife, Harry stated:

It makes me feel as if my pain is responsible for her emotional pain (...) it makes me feel uncomfortable, very uncomfortable sometimes. Particularly when the pain is prolonged, and I know that she's suffering because you can see that it's impacting on her $(\ldots)$ because she loves me she doesn't want me to be so distressed and knowing that I am distressed with all the pain and there's nothing she can do. [Harry]

Harry's concerns with burdening his wife lay in the impact upon her well-being and the psychological distress that it caused for her, with a degree of guilt and responsibility voiced.

The theme of possibly choosing social isolation over the sense of being a burden also arose in Sharon's interview, about her relationships with a therapist:

I was talking to my therapist about it but uh, I'm not any more very much because ... how much can you talk about pain? It's just pain. Nobody wants to hear about pain over and over and over again [laughter] so no I guess I don't really talk too much about pain. [Sharon] 
Sharon discussed a boundary she placed upon her decisions to talk to others about her pain, restricting opportunities to discuss it order to protect her therapist, or possibly to protect herself from anticipated judgement. Sharon implied that talking about pain was likely to elicit negative social consequences, such as boredom, for the listener.

\section{Discussion}

This study set out to investigate the subjective meanings and experiences of chronic pain in SCI patients. All participants identified NP as the most troublesome pain experience, although some experienced several sources of pain. Participants felt that there was a gap between the care that they received and the care that they desired; this caused feelings of being unheard, and resentment of the apparent reliance upon medication that was unsuitable. Participants also felt that they were locked in battle with their pain, struggling for life control, with acceptance apparently mediating this relationship. They also voiced concerns for their social well-being and implied feared, or even shameful, consequences of talking about the impact of pain to people without SCI. Many chose to avoid discussing pain with people without SCI, with the potential to increase isolation. Non-disclosure appeared to avoid other unwanted social or emotional consequences such as fear of burden, or potential negative judgement.

Each of these themes draws attention to the potential for NP to cause psychological distress in some people, including anxiety and depression, with hopelessness and lack of personal agency key themes among those most distressed. These participants visualised their pain as an endless experience in which they were entrapped, with little hope for regaining a positive outlook or social presence in the future, using catastrophic language and imagery. Other participants voiced that they had found ways to live despite the presence of pain. These participants focused 
predominantly on the futility of trying to beat pain. Although level and quality of articulation differed amongst participants, they raised the themes spontaneously, reinforcing their prominence and pervasiveness within each individual's experience.

The first sub-ordinate theme voiced by participants was the apparent reliance upon medication, which participants felt was ineffective and unhelpful. As a result of the perceived reliance, fears of dependency, and the occurrence of undesirable sideeffects such as sedation and interrupted cognitive performance, some participants made conscious decisions not to adhere to their drug regimes, choosing to reduce their dose or to abandon them completely. This appears to be a common occurrence in chronic pain populations [39], and has been previously identified as a problem for those with SCI [31]. This suggests that SCI patients with NP are engaged in a 'trade-off', willing to give up pain relief in favour of fewer side-effects and freedom from anxieties, in the same way as non-SCI chronic pain patients [40].

The second sub-ordinate theme that participants voiced was related to patients' negative relationships with HCPs, who continued to offer treatment that they found inadequate. This mirrors findings in the general chronic pain literature. Eccleston, Williams, and Rogers [41] suggested that relationships with HCPs could mediate distress in chronic pain patients, whilst Coulter \& Fitzpatrick [42] suggest that patient dissatisfaction may result in reduced adherence to medication. Hansson, Fridlund, Brunt, Hansson, and Rask [43] studied chronic pain patients' experiences of the healthcare system, finding that staff tended to focus upon their areas of expertise, such as medication, potentially ignoring psychosocial difficulties. This theme would suggest that continuing with this strategy is unhelpful for any chronic pain sufferer, regardless of the possible medical aetiology of the pain. 
The third sub-ordinate theme arising within the chasm reflects this, suggesting that patients would welcome HCPs accepting pain as the patient describes it, and actively considering other ways of enhancing patient control. Pain-related distress and frustration may be reduced if HCPs accredit patients, and offer them empowerment and responsibility. Collaborative efforts between patients and staff, in which HCPs can provide medical knowledge and support as and when it is required [44], such that patients can make informed decisions and drive their own rehabilitation [45]. It would be interesting to explore why the collaborative ethos so embedded in SCI rehabilitation and goal planning [46] appears to be absent from communication about NP, at least from the perspective of participants. This theme echoes research regarding a link between the quality of the HCP-patient relationship and medication adherence [47]. This theme suggests that, currently, a discrepancy exists between what sort of response SCI patients want from HCP's in relation to their experience of NP and what they are offered. This discrepancy was also identified by Lofgren \& Norrbrink [28], who explored the experiences of people with SCI when offered specific, collaborative pain management interventions based on evidence from general chronic pain population.

The concept of the battle for control was another prominent super-ordinate theme, dictating an internal struggle for ultimate life control between the individual and their pain, suggesting that there is a psychological aspect of the pain experience after SCI that may be managed. More pain acceptance, and beliefs that the pain is not always in control, was associated with less expressed distress and pain related disruption. Where individuals feel that pain is in their control, quality of life, community reintegration, and physical and psychological outcomes are improved [12]. Lower acceptance appeared alongside struggles to obtain life control and potential catastrophising, with those 'losing the battle to pain' tending be associated with tortuous 
metaphors and imagery. This polarisation of language may have resulted from an attempt to convey the extent of their distress to others.

These fearful thoughts may be considered as taking the form of catastrophic thinking, a well documented phenomena in research on non-NP populations. This appraisal style considers pain as a threat, which Walsh and Radcliffe [48] suggest may contribute to its disruptiveness and intensity, and may increase physical and psychological disability in chronic low back pain. The emotive nature of images in this theme may have informed a heightened vigilance towards pain, thus causing increased pain intensity and disruption, as documented in the general chronic pain literature [49].

This theme echoes results of a Grounded Theory analysis of acceptance in those with SCI-specific NP [29], finding that acknowledging the permanence of pain, and the ability to live with pain present, reduced suffering. This also indicates that the already established relationship between acceptance and adjustment to pain [50] exists in the SCI population, and such pain acceptance may be associated with reduced pain perception and reduced distress [51]. This suggests that a simple target for interventions with SCI patients might be fostering a sense of control, shifting focus away from the emphasis on reducing pain intensity to responses to distress, and the issue of focussing on pursuing valued activities, and identity. Indeed, outpatient engagement in acceptance-based therapies in order to reduce catastrophic thoughts may have a much greater impact on psychological well-being than pain intensity alone [52]. The need for acknowledgment of distress and life restriction was a key theme in participants' wishes for treatment.

The third super-ordinate theme arising from the analysis identified that there exists a simultaneous occurrence of social unison with other SCI individuals, and social isolation from the available able-bodied social support. The social context of chronic 
pain is influential in adjustment [53], and this result may contribute to this idea. In line with results found by Dickson, Ward, O’Brien, Allen, and O'Carroll [54], outpatients articulated experiencing a connection with other SCI patients, bonded by their shared experiences, but felt that they lost this camaraderie and community spirit upon discharge. This loss of camaraderie may serve as a barrier to community reintegration, adjustment and pain acceptance following discharge from a spinal unit for those whose distress remains heightened by the presence of pain.

Participants in this study voiced their attempts at social withdrawal in order to prevent their pain from burdening their friends and families. Further, participants who chose to only talk to those who understood their pain may have contributed to their own isolation. Closs, Staples, Reid, Bennett, and Briggs [55], found comparable results in chronic pain patients, who also engaged in social withdrawal as a result of concern for the impact of their pain on social relationships, and increased self-perceived burden (SPB). This SPB may have a negative impact upon psychological wellbeing and is predictive of suicidal ideation [56]. Feelings of SPB are important to target in pain management, particularly due to its positive correlation with pain intensity, depression and anxiety $[57,58]$, and its impact on the well-being of patient friends and families, who are at increased risk of suffering depression and anxiety [59]. Outpatient social support through the use of peer and family mentoring discussions may therefore be informed by staff knowledge of ongoing pain, in order to improve such social support.

The experience of chronic NP shares a number of similarities with non-SCI chronic pain, framed within the biopsychosocial model $[19,60]$. Multidisciplinary pain management programmes (PMPs) have shown general effectiveness for non-SCI chronic pain, yet SCI-specific pain has remained resistant to these [18], suggesting the need to tailor PMPs to the specific needs of the SCI population. However, this data 
suggests that even interventions in routine clinical follow-up of SCI patients, rather than in specific PMPs, may have a potential impact on distress. Both the present study, and previous content analysis of questionnaires completed by SCI patients [61], indicate that those living with SCI have a desire for dialogue with those working with them, and that HCPs would benefit from listening to each individual's personal story. Focus upon improving the sense of life control, acceptance, living well despite pain, and addressing social isolation may also be of benefit to SCI patients' well-being.

A particularly useful intervention for this population may be that of mindfulness, which has a well-documented evidence base for increasing pain tolerance and reducing distress in non-SCI chronic pain populations [62]. Mindfulness may be useful for those wishing to reduce or avoid medication use, such as participants in this study, due to its ability to shift the focus to experience and reduce the desire for pain medication as a means to solve a problem [63]. Further research has found benefits of mindfulness in terms of physical and psychological well-being [64], and interpersonal relationships [65]. Comparable to these findings, the only study examining state mindfulness in those with SCI suggested that being more mindful reduced the use of avoidance techniques in response to negative events, and depressive symptoms, resulting in increased positive $\operatorname{mood}[66]$.

\section{Limitations \& Future Research}

The nature of the IPA methodology limits the degree to which conclusions can be drawn about any causal links between themes. It may be beneficial for future research to explore quantitative perceptions of the quality of patients' interpersonal relationships with family, friends, the SCI community, and HCPs, as well as quantitative measures of catastrophising, adjustment to SCI, and perceived life control, in order to validate the themes presented here. It may also be of benefit to interview 
HCP's who work with SCI patients, in order to understand what barriers to implementing a biopsychosocial care pathway for NP exist, and how these might be overcome.

It may be argued that the small sample may not have been a good representation of the general SCI population. It was also a self-selecting sample, suggesting that the participants may have been more willing to talk to a stranger about their pain than the rest of the non-volunteering population. Data from another outpatient sample may be useful to explore if the themes are replicable. Previous qualitative research, including content analysis and Grounded Theory, has been conducted with the SCI population. IPA has not previously been utilised to enhance our understanding of SCI-specific NP, and this study allowed for a deeper level of understanding of the experience to be reached by listening to the stories of those living with it, and allowing them to articulate the most important issues to them. There was also value in linking lived experience with some of the published quantitative and qualitative literature. Social factors, including relationships with HCP's, and communication about medication, were central issues to participants' experiences but are relatively under-represented in the quantitative literature compared to study of personal, internal cognitive factors such as perceived control and catastrophising.

\section{Acknowledgements}

We would like to thank all of the participants and staff at The National Spinal Injuries Centre, Stoke Mandeville Hospital, for their time and co-operation.

\section{Declaration of Interests}

None. 


\section{References}

1. Kennedy P, Frankel H, Gardner B, Nuseibeh I. Factors associated with acute and chronic pain following traumatic spinal cord injuries. Spinal Cord 1997;35:814817.

2. Modirian E, Pirouzi P, Soroush M, Karbalaei-Esmaeili S, Shojaei H, Zamani H. Chronic pain after spinal cord injury: results of a long-term study. Pain Medicine 2010;11(7):1037-1043.

3. Werhagen L, Norrbrink C, Hultling C, Molander C. Neuropathic pain after traumatic spinal cord injury - relations to gender, spinal level, completeness, and age at the time of injury. Spinal Cord 2004;42:665-673.

4. Siddall PJ. Management of neuropathic pain following spinal cord injury: now and in the future. Spinal Cord 2009;47:352-359.

5. Bennett M. The LANSS Pain Scale: the Leeds assessment of neuropathic symptoms and signs. Pain 2001;92(1-2):147-157.

6. Jensen MP, Hoffman AJ, Cardenas DD. Chronic pain in persons with spinal cord injury: A survey and longitudinal study. Spinal Cord 2005;43:704-712.

7. Siddall PJ, McClelland JM, Rutkowski SB, Cousins MJ. A longitudinal study of the prevalence and characteristics of pain in the first 5 years following spinal cord injury. Pain 2003;103:249-257.

8. Widerstrom-Noga EG, Felipe-Cuervo E, Broton JG, Duncan RC, Yezierski RP. Perceived difficulty in dealing with consequences of spinal cord injury. Archives of Physical Medicine and Rehabilitation 1999;80(5):580-586.

9. Murray RF, Asghari A, Egorov DD, Rutkowski SB, Siddall PJ, Soden RJ, Ruff R. Impact of spinal cord injury on self-perceived pre- and post-morbid cognitive, emotional and physical functioning. Spinal Cord 2007;45(6):429-36. 
10. Westgren N, Levi R. Quality of life and traumatic spinal cord injury. Archives of Physical Medicine and Rehabilitation 1998;79(11):1433-39.

11. Putzke JD, Richards JS, Hicken BL, DeVivo MJ. Interference due to pain following spinal cord injury: Important predictors and impact on quality of life. Pain 2002;100:231-242.

12. Craig AR, Tran Y, Middleton J. Psychological morbidity and spinal cord injury: A systematic review. Spinal Cord 2009;47:108-114.

13. Hoffman JM, Bombardier CH, Graves DE, Kalpakjian CZ, Krause JS. A longitudinal study of depression from 1 to 5 years after spinal cord injury. Archives of Physical Medicine and Rehabilitation 2011;92:411-418.

14. Ataoglu E, Tiftik T, Kara M, Tunc H, Ersoz M, Akkus S. Effects of chronic pain on quality of life and depression in patients with spinal cord injury. Spinal Cord 2013;51(1):23-26.

15. Campbell LC, Clauw DJ, Keefe FJ. Persistent pain and depression: A biopsychosocial perspective. Biological Psychiatry 2003;54:399-409.

16. Banks SM, Kerns RD. Explaining high rates of depression in chronic pain: A diathesis-stress framework. Psychological Bulletin 1996;119:95-110.

17. Ullrich PM, Lincoln RK, Tackett MJ, Miskevics S, Smith BM, Weaver FM. Pain, Depression, and Health Care Utilization Over Time After Spinal Cord Injury. Rehabilitation Psychology 2013;58(2):158-165.

18. Nicholson Perry K, Nicholas MK, Middleton J, Siddall PJ. Psychological characteristics of people with spinal cord injury-related persisting pain referred to a tertiary pain management center. Journal of Rehabilitation Research and Development 2009;46(1):57-68. 
19. Engel GL. The need for a new medical model: a challenge for biomedicine. Science 1977;196:129-136.

20. Cardenas DD, Jensen MP. Treatments for chronic pain in persons with spinal cord injury: a survey study. Journal of Spinal Cord Medicine 2006;29:109-117.

21. Siddall PJ, Middleton JW. A proposed algorithm for the management of pain following spinal cord injury. Spinal Cord 2006;44:67-77.

22. Widerstrom-Noga EG, Finnerup NB, Siddall PJ. Biopsychosocial perspective on a mechanisms-based approach to assessment and treatment of pain following spinal cord injury. Journal of Rehabilitation Research and Development 2009;46(1):1-12.

23. Molton IR, Stoelb BL, Jensen MP, Ehde D, Raichle KA, Cardenas DD. Psychosocial factors and adjustment to chronic pain in spinal cord injury: Replication and cross-validation. Journal of Rehabilitation Research Development 2009;46(1):31-42.

24. Boothby JL, Thorn BE, Overduin LY, Ward LC. Catastrophizing and perceived partner responses to pain. Pain 2004;109(3):500-6.

25. Romano JM, Turner JA, Jensen MP, Friedman LS, Bulcroft RA, Hops H, Wright SF. Chronic pain patient-spouse behavioural interactions predict patient disability. Pain 1995;63(3):353-60.

26. Rees T, Smith B, Sparkes AC. The influence of social support on the lived experiences of spinal cord injured sportsmen. Sport Psychologist $2003 ; 17(2): 135-156$.

27. Sparkes AC, Smith B. Men, spinal cord injury, memories and the narrative performance of pain. Disability and Society 2008;23(7):679-690. 
28. Lofgren M, Norrbrink C. "But I know what works"--patients' experience of spinal cord injury neuropathic pain management. Disability and Rehabilitation 2012;34(25):2139-2147.

29. Henwood P, Ellis JA, Logan J, Dubouloz CJ, D’Eon J. Acceptance of chronic neuropathic pain in spinal cord injured persons: a qualitative approach. Pain Management Nursing: Official Journal of the American Society of Pain Management Nurses 2012;13(4):215-222.

30. Norman C, Bender JL, Macdonald J, Dunn M, Dunne S, Siu B, Hunter J. Questions that individuals with spinal cord injury have regarding their chronic pain: A qualitative study. Disability \& Rehabilitation 2010;32(2):114-124.

31. Henwood P, Ellis JA. Chronic neuropathic pain in spinal cord injury: the patient's perspective. Pain Research \& Management: The Journal of the Canadian Pain Society $=$ Journal De La Société Canadienne Pour Le Traitement De La Douleur 2004;9(1):39-45.

32. Norrbrink C, Löfgren M, Hunter JP, Ellis J. Patients' perspectives on pain. Topics in Spinal Cord Injury Rehabilitation 2012;18(1):50-56.

33. Barnes C, Mercer G, Shakespeare T. Exploring disability: A sociological introduction. Cambridge, UK: Polity Press; 1999.

34. Smith JA. Beyond the divide between cognition and discourse: Using interpretative phenomenological analysis in health psychology. Psychology \& Health 1996;11(2):261-271.

35. Shaw I. Embedding reflexivity within experiential qualitative psychology. Qualitative Research in Psychology 2010;7(3):233-243.

36. International Association for the Study of Pain [Internet]. Classification of Chronic Pain, Second Edition (Revised); 2011 - [cited 2014 Aug 7]; Available 
from:

http://www.iasppain.org/PublicationsNews/Content.aspx? ItemNumber=1673\&n $\underline{\text { avItemNumber }=677}$

37. Smith JA, Flowers P, Larkin M. Interpretative Phenomenological Analysis:

Theory, Method and Research. London: Sage; 2009.

38. Brocki JJM, Wearden AJ. A critical evaluation of the use of interpretative phenomenological analysis (IPA) in health psychology. Psychology and Health 2006;21(1):87-108.

39. Broekmans S, Dobbels F, Milisen K, Morlion B, Vanderschueren S. Medication adherence in patients with chronic non-malignant pain: is there a problem? European Journal Of Pain 2009;13:115-123.

40. Gregorian RS, Gasik A, Kwong WJ, Voeller S, Kavanagh S. Importance of Side Effects in Opioid Treatment: A Trade-Off Analysis With Patients and Physicians. Journal of Pain 2010;11(11):1095-1108.

41. Eccleston C, Williams AC, Rogers WS. Patients' and professionals' understandings of the causes of chronic pain: Blame, responsibility and identity protection. Social Science \& Medicine 1997;45:699-709.

42. Coulter A, Fitzpatrick R. The patients' perspective regarding appropriate health care. In: Albreccht G, Fitzpatrick R, Scrimshaw SC, editors. The Handbook of social studies in health and medicine. London: Sage Publications; 2003. p. 454464.

43. Hansson KS, Fridlund B, Brunt D, Hansson B, Rask M. The meaning of the experiences of persons with chronic pain in their encounters with the health service. Scandinavian Journal of Caring Sciences 2011;25:444-450. 
44. Clarke AM. In First National Conference of the Spinal Network. Christchurch, New Zealand 2001.

45. Barrie J. Patient empowerment and choice in chronic pain management. Nursing Standard 2011;25(31):38-41.

46. Duff J, Evans MJ, Kennedy P. Goal planning: a retrospective audit of rehabilitation process and outcome. Clinical Rehabilitation 2004;18(3):275-286.

47. Parsons S, Harding G, Breen A, Foster N, Pincus T, Vogel S, Underwood M. The influence of patients' and primary care practitioners' beliefs and expectations about chronic musculoskeletal pain on the process of care: a systematic review of qualitative studies. Clinical Journal of Pain 2007;23:91-98.

48. Walsh DA, Radcliffe JC. Pain beliefs and perceived physical disability of patients with chronic low back pain. Pain 2002;97(1-2):23-31.

49. Crombez G, Van Damme S, Eccleston C. Hypervigilance to pain: an experimental and clinical analysis. Pain 2005;116(1):4-7.

50. McCracken LM. Learning to live with the pain: acceptance of pain predicts adjustment in persons with chronic pain. Pain 1998;74:21-27.

51. Vowles KE, McCracken LM, Eccleston C. Patient functioning and catastrophizing in chronic pain: The mediating effects of acceptance. Health Psychology 2008;27(2, Suppl):S136-S143.

52. Cuff L, Fann JR, Bombardier CH, Graves DE, Kalpakjian CZ. Depression, pain intensity, and interference in acute spinal cord injury. Topics in Spinal Cord Injury Rehabilitation 2014;20(1):32-39.

53. Romano J, Cano A, Schmaling K. Assessment of couples and families with chronic pain. In: Turk DC, Melzack R, editors. Handbook of Pain Assessment. 3rd ed. New York, NY: Guildford Press; 2011. p 98-116. 
54. Dickson A, Ward R, O’Brien G, Allan D, O’Carroll R. Difficulties adjusting to post-discharge life following a spinal cord injury: An interpretative phenomenological analysis. Psychology, Health \& Medicine 2011;16(4):463474.

55. Closs SJ, Staples V, Reid I, Bennett MI, Briggs M. The impact of neuropathic pain on relationships. Journal of Advanced Nursing 2009;65(2):402-411.

56. Wilson KG, Chocinov HM, McPherson CJ, Skirko MG, Allard P, Chary S, Kuhl D. Desire for euthanasia or physician-assisted suicide in palliative cancer care. Health Psychology 2007;26:314-323.

57. Kowal J, Wilson KG, McWilliams LA, Peloquin K, Duong D. Self-perceived burden in chronic pain: Relevance, prevalence, and predictors. Pain 2012;153(8):1735-1741.

58. Wilson KG, Kowal J, Henderson PR, McWilliams LA, Peloquin K. Brief Report: Chronic Pain and the Interpersonal Theory of Suicide. Rehabilitation Psychology 2013;58(1):111-115.

59. Kolakowsky-Hayner SA, Kishore R. Caregiver functioning after traumatic injury. NeuroRehabilitation 1999;13:27-33.

60. Turk DC, Monarch ES. Biopsychosocial Perspective on Chronic Pain. In: Turk DC, Gatchel RJ, editors. Psychological Approaches to Pain Management, Second Edition: A Practitioner's Handbook. Guildford Publications; 1996. p 329.

61. Warms CA, Marshall HM, Hoffman AJ, Tyler EJ. There are a few things you did not ask about my pain: writing on the margins of a survey questionnaire. Rehabilitation Nursing: The Official Journal of the Association of Rehabilitation Nurses 2005;30(6):248-256. 
62. Kabat-Zinn J. Mindfulness-Based Interventions in Context: Past, Present, and Future. Clinical Psychology: Science and Practice 2003;10(2):144-156.

63. Garland EL, Manusov EG, Froeliger B, Kelly A, Williams JM, Howard MO. Mindfulness-Oriented Recovery Enhancement for Chronic Pain and Prescription Opioid Misuse: Results From an Early-Stage Randomized Controlled Trial. J. of Consulting and Clinical Psychology 2014;82(3):448-459.

64. Teixeira ME. Meditation as an Intervention for Chronic Pain: An Integrative Review. Holistic Nursing Practice 2008;22(4):225-234.

65. Brown KW, Ryan RM, Creswell JD. Mindfulness: Theoretical Foundations and Evidence for its Salutary Effects. Psychological Inquiry 2007;18(4): 211-237.

66. Skinner TC, Roberton T, Allison GT, Dunlop S, Bucks RS. Experiential Avoidance, Mindfulness and Depression in Spinal Cord Injuries: A Preliminary Study. The Australian Journal of Rehabilitation Counselling 2010;16(1):27-35. 
Table 1. Participant characteristics $(n=8)$

\begin{tabular}{|c|c|c|c|c|c|c|c|c|}
\hline Participant* & Age & $\begin{array}{l}\text { Employment } \\
\text { status }\end{array}$ & $\begin{array}{l}\text { Marital } \\
\text { status }\end{array}$ & Cause of injury & $\begin{array}{l}\text { Time } \\
\text { since } \\
\text { injury } \\
\text { (years) }\end{array}$ & $\begin{array}{l}\text { Level of } \\
\text { Injury }\end{array}$ & Pain location(s) & $\begin{array}{l}\text { Average } \\
\text { Pain } \\
\text { Intensity } \\
(\text { VAS } * * *)\end{array}$ \\
\hline James & 38 & Part-time & Married & RTA** & 2 & T3-T4 & Left leg, chest & 8 \\
\hline Daniel & 26 & Full-time & Cohabiting & Gun shot wound & 3 & L1-L2 & Right leg & 9 \\
\hline Harry & 65 & Unemployed & Married & RTA & 32 & $\mathrm{C} 5-\mathrm{C} 6$ & Right hip, back & $8-10$ \\
\hline Rebecca & 44 & Unemployed & Single & RTA & 21 & $\mathrm{C} 4-\mathrm{C} 5$ & Whole body & 10 \\
\hline Dave & 77 & Retired & Widowed & Fall & 15 & $\mathrm{~T} 12$ & Legs & 5 \\
\hline Emma & 42 & Part-time & Married & $\begin{array}{l}\text { Non-traumatic } \\
\text { condition }\end{array}$ & 1 & C4-T9 & Legs, abdomen & $3-4$ \\
\hline Sharon & 49 & Unemployed & Divorced & $\begin{array}{l}\text { Non-traumatic } \\
\text { condition }\end{array}$ & 1 & $\mathrm{C} 4$ & Whole body & 6 \\
\hline Sean & 31 & Part-time & Single & Traumatic & 10 & $\mathrm{C} 5-\mathrm{C} 6$ & Abdomen, legs & 4 \\
\hline
\end{tabular}

*All names changed to preserve anonymity.

** Road Traffic Accident

$* * *$ Visual Analogue Scale of pain intensity, ranging from 0 (no pain) to 10 (pain as bad as it could be) 
Table 2. Interview Schedule.

1. Tell me about your experience of pain since your spinal cord injury.

- Where is it located?

- How does it feel at best/at worst?

- How often does it present itself?

2. How have you been informed about your pain?

- Was this helpful?

3. What techniques do you use to cope with your pain, if any?

- What is the most effective strategy for managing your pain?

4. What is your life like since experiencing SCI-specific pain?

- How does pain affect your everyday life?

- How have other reacted to your pain?

- Are there any activities you do differently now as a result of your pain?

5. How do you think your pain will affect your future, if at all?

6. Is there anything else you would like to add to the discussion? 
Table 3. Super-ordinate themes and corresponding sub-ordinate themes.

\begin{tabular}{l|l|l}
\hline $\begin{array}{l}\text { The Chasm Between Biomedical } \\
\text { Perspectives and Patient Beliefs } \\
\text { and Needs }\end{array}$ & $\begin{array}{l}\text { The Battle for Ultimate Agency } \\
\text { in Life }\end{array}$ & $\begin{array}{l}\text { The Coexistence of Social } \\
\text { Cohesion and Social Alienation }\end{array}$ \\
\hline $\begin{array}{l}\text { Excessive Reliance on } \\
\text { Insufficient Medication }\end{array}$ & I am Winning & $\begin{array}{l}\text { SCI Population are United but } \\
\text { Alone in their Experience }\end{array}$ \\
$\begin{array}{l}\text { Losing Faith in Healthcare } \\
\text { Professionals }\end{array}$ & $\begin{array}{l}\text { Painful Self as an Affliction on } \\
\text { Social Relationships }\end{array}$ \\
$\begin{array}{l}\text { Lack of Input into own Care } \\
\text { Pang }\end{array}$ &
\end{tabular}




\section{Disability and Rehabilitation - Decision on Manuscript ID TIDS- 08-2014-022.R1}

onbehalfof+davemuller+suffolk.ac.uk@manuscriptcen...

To: JASMINE HEARN

$22-$ Dec-2014

Dear Miss Hearn:

Ref: Living with chronic neuropathic pain after spinal cord injury: An Interpretative Phenomenological Analysis of community experience

Our referees have now considered your paper and have recommended publication in Disability and Rehabilitation. We are pleased to accept your paper in its current form which will now be forwarded to the publisher for copy editing and typesetting.

You will receive proofs for checking, and instructions for transfer of copyright in due course.

The publisher also requests that proofs are checked and returned within 48 hours of receipt.

Thank you for your contribution to Disability and Rehabilitation and we look forward to receiving further submissions from you.

Sincerely,

Professor Muller

Editor in Chief, Disability and Rehabilitation

davemuller@suffolk.ac.uk 